\title{
A renoprotective role of chitosan against lithium-induced renal toxicity in rats
}

\author{
Wael Mahmoud Aboulthana ${ }^{1 *}$ (D) and Noha El-Sayed Ibrahim²
}

\begin{abstract}
Background: Lithium (Li) is considered as the first therapeutic line for treatment of bipolar affective disorders and manic-depressive illness. Renal toxicity can be categorized as the most common undesirable side effect of Li therapy. Therefore, the present study aimed to reveal efficiency of chitosan (CS) as a natural chelator against renal toxicity induced as a result of $\mathrm{Li}$ injection. During current experiment, the renal functions (urea, creatinine, blood urea nitrogen $(B \cup N)$, uric acid and total protein) were determined in serum samples. The urinary excretion of $\mathrm{N}$-acetyl- $\beta$-Dglucosaminidase (NAG) was assayed through measuring its level in urine samples. Moreover, markers of the oxidative stress (superoxide dismutase (SOD), catalase (CAT), glutathione peroxidase (GPx), reduced glutathione $(G S H)$ and lipid peroxidation product (LPO)) were assessed in renal tissues. In addition, histopathological and ultrastructural examinations were carried out in that tissue.

Results: It was found that $\mathrm{Li}$ injection caused significant $(P<0.05)$ elevation in serum urea, creatinin and BUN levels associated with decline in uric acid and T. protein. Moreover, Li increased the urinary excretion of NAG significantly $(P<0.05)$. Administration of CS orally restored levels of these measurements to normalcy in CS pre-treated group through lowering urea, creatinin, BNU levels and urinary excretion of NAG with enhancing uric acid and T. protein levels.

On the other hand, it was found that Li caused significant $(P<0.05)$ elevation in the LPO level associated with decline in activity of the antioxidant system in the renal tissues. Likewise, it caused severe alterations in the renal levels at histopathological and ultrastructural levels. The treatment with CS reduced the renal LPO associated with stimulating the antioxidant system through increasing levels of SOD, CAT, GPx and GSH in addition to its beneficial role against the histopathological abnormalities.
\end{abstract}

Conclusions: The CS exhibited promising role in the protection against the oxidative stress and renal toxicity induced as a result of $L i$ injection.

Keywords: Lithium therapy, Renal toxicity, Chitosan, Antioxidants, Ultrastructure

\section{Background}

Lithium (Li) is a toxic monovalent alkaline metal. It occurs naturally in all soils, surface and drinking water. Moreover, it accumulates in marine animals, algae and vegetables which represent the primary dietary Li sources and may contribute from $66 \%$ to 90\% of the total Li intake (Curran and Ravindran 2014; McCartney et al. 2014). Lithium carbonate has been used as an invaluable drug to cure bipolar

\footnotetext{
* Correspondence: wmkamel83@hotmail.com

${ }^{1}$ Biochemistry Department, Genetic Engineering and Biotechnology Division, National Research Centre (Affiliation ID: 60014618), P.O. 12622, Dokki, Giza, Egypt Full list of author information is available at the end of the article
}

disorders and manic-depressive illness for more than 60 years (Grunze et al. 2010; Calkin and Alda 2012; Vieta and Valenti 2013). Moreover, it was reported that this drug used as chronic treatment to prevent development of Alzheimer's disease (Forlenza et al. 2011) and for treatment of refractory depression (Edwards et al. 2013; Cleare et al. 2015). During treatment of bipolar disorders, the prolonged exposure to Li exhibits toxic effects on several biological systems (McCartney et al. 2014; Albert et al. 2014). The gastrointestinal, renal, neurological and endocrine disorders belong to the numerous undesirable side effects occurred as a result of Li therapy (Adityanjee and Munshi 2005; Kalantari et al. 2015). 
As suggested recently by Close et al. (2014) and supported by Bocchetta et al. (2015), absorption of Li occurs completely in the gastrointestinal tract and filtered through the glomeruli then reabsorbed in the proximal tubule which represents the primary site at which the reabsorption process occurs. It accumulates in the collecting tubule and interferes with capacity of the collecting tubule (especially the cortical portion) in both kidneys to generate cyclic adenosine monophosphate as response of stimulation of antidiuretic hormone (Erden et al. 2013; Oruch et al. 2014; Clos et al. 2015).

Tubulointerstitial nephropathy is the most common deleterious side effect of $\mathrm{Li}$ on renal functions; however, the renal ischaemia occurred by pathogenetic mechanism through damage of the mitochondria and endoplasmic reticulum (Markowitz et al. 2000). It was stated that the mechanism by which $\mathrm{Li}$ induced nephrotoxicity is still poorly understood (Oktem et al. 2005). There were no procedures suitable to be established for the early diagnosis of Li nephrotoxicity (Ida et al. 2001). Moreover, renal impairment may not be recovered even after interruption of $\mathrm{Li}$ therapy (Markowitz et al. 2000).

It is well known that urinary $\mathrm{N}$-acetyl- $\beta$-D-glucosaminidase (NAG) is used as sensitive marker of renal tubular injury and elevation of its level has been associated with Li-induced renal tubular damage (Chmielnicka and Nasiadek 2003). It has been suggested that oxidative stress belongs to the most important mechanisms by which Li exhibit its adverse effects (Oktem et al. 2005). It increased generation of the reactive oxygen species (ROS) such as superoxide and nitric oxide (NO). These reactive species exhibit their adverse role and contribute to the pathophysiology of Li-induced renal impairment through increasing the lipid peroxidation in kidney tissue and hence tissue injury (Sawas et al. 1986). These continuously produced ROS are scavenged by antioxidative system which can be divided into enzymatic (superoxide dismutase (SOD), catalase (CAT) and glutathione peroxidase (GPx)) and non-enzymatic (reduced glutathione (GSH)) (Draper and Hadley 1990).

It is worth to mention that antioxidants have attracted much attention as useful alternative medicines for treating or preventing disorders related to the abnormal lifestyle (Rajkapoor et al. 2008). The synthetic antioxidants have restriction for medicinal uses, as they are suspected to be carcinogenic (ElFar and Taie 2009). The recent studies directed to search in the nature to select one of them to be suitable for the therapeutic purposes as antioxidants in reducing free radical-induced tissue injury (Erdemoglu et al. 2006). In 2005, Efrati et al. (2004) suggested $\mathrm{N}$-Acetylcysteine to ameliorate renal failure induced by $\mathrm{Li}$ in rats. Also, it was showed that caffeic acid phenethyl ester exhibits a protective effect against damages of the renal tubules occurred as a result of oxidative stress in Li-treated rats (Oktem et al. 2005).

Chitosan (CS), a linear and semi-crystalline polysaccharide, is naturally occurring non-toxic polymeric compounds derived from chitin which is the major component of the crustaceans' shells (e.g., crab, shrimp, prawn, lobster, and crawfish) (Xia et al. 2011). It is consisting to $(1 \rightarrow 4)$-2-acetamido-2-deoxy- $\beta$-D-glucan ( $\mathrm{N}$-acetyl $\mathrm{D}$ glucosamine) and $(1 \rightarrow 4)$-2-amino-2-deoxy- $\beta$-D-glucan (D-glucosamine) which randomly distributed. The CS grade depends in its structure on content of the acetylated component (Rinaudo 2006; Dong et al. 2010). Due to its special structure and biochemical property, it has received various applications in biomedicine, agriculture and environmental field (Park et al. 2003). Physiologically, CS is considered a dietary fiber because it cannot be degraded by digestive enzymes (Harish Prashanth and Tharanathan 2007). Furthermore, it is characterized by its excellent biological activity such as high biocompatibility, biodegradability, immunogenicity and low toxicity. Therefore, it promises for being a perfect biological material and pharmaceutical formulation (Xia et al. 2011; Dong et al. 2010). In recent years, CS has attracted much attention because of various biological activities related to the antioxidant activity of it and its hydrolyzed products. It exhibits hepatoprotective effects (Jeon et al. 2003), hypocholesterolemic, antiosteoarthritic (Samarasinghe et al. 2014), antitumor (Qi and Xu 2006), antimetastatic (Shen et al. 2009), antiulcer, immunostimulatory (Neimert-Andersson et al. 2011) and antibacterial activities (No et al. 2002). The physicochemical properties of the CS structure may refer to presence of the reactive functional groups that correlate with their chelation and flocculation efficiency (Gamage and Shahidi 2007; Renault et al. 2009). It has been extensively studied for its cation-binding ability (Bravo-Osuna et al. 2007).

CS exerted its high hydrophilic ability to attract the cations. The high hydrophilicity may refer to large number of hydroxyl groups in its active sites, enabling it to attract those cations (Crini and Badot 2008). For this reason, the present study aimed to reveal the CS efficiency as a natural chelator to resist the renal toxicity induced by Li injection for therapeutic purposes.

\section{Materials and methods}

Materials: chemicals, reagents and kits

All chemicals and reagents were of analytical grade and of highest purity. Chitosan, Lithium carbonate $\left(\mathrm{Li}_{2} \mathrm{CO}_{3}\right)$ and Tris buffer were purchased from Sigma-Aldrich. Hematoxylin and Eosin stains were obtained from SRL, India. 2-Thio-barbituric Acid 
(TBA) was procured from Sigma Chemicals Company (London, UK). Kits for urea, creatinine and total protein were obtained from Spectrum Diagnostics Egyptian Company for Biotechnology (Cairo, Egypt).

\section{Animals \\ Forty-eight healthy adult male Wistar albino rats (mean weight $230 \pm 30 \mathrm{~g}$ ) were housed in six polypropylene cages (eight per cage) under hygienic conditions. The animals were maintained at normal room temperature at $25 \pm 2{ }^{\circ} \mathrm{C}$. A commercially balanced diet and tap water were provided ad libitum for 1 week before start of the experiment.}

\section{Experimental design}

The rats were randomly divided into six experimental groups. The first group (control): rats were allowed to feed with normal diet as ad libitum and received distilled water for 30 days. The second group (CS-treated group): rats were fed with normal diet associated with oral gavage treatment with CS at a dose of $200 \mathrm{mg} / \mathrm{kg}$ b.w./day for 14 days (Jeon et al. 2003). The third group (Lithium-treated): rats were injected intraperitoneally (i.p.) with $\mathrm{Li}_{2} \mathrm{CO}_{3}$ solution $\left(25 \mathrm{mg} / \mathrm{kg} \mathrm{Li} \mathrm{LO}_{3}\right.$ solution in saline) twice daily for 30 days (Leschiner et al. 2000). The fourth group (CS pre-treated): rats were treated with CS orally for 14 days followed be injection with $\mathrm{Li}_{2} \mathrm{CO}_{3}$ solution i.p. twice daily for another 30 days. The fifth group (CS simultaneous-treated): rats were injected with $\mathrm{Li}_{2} \mathrm{CO}_{3}$ solution i.p. twice daily for 30 days in coincide to treatment with CS orally for 14 days. The sixth group (CS post-treated): rats were injected with $\mathrm{Li}_{2} \mathrm{CO}_{3}$ solution i.p. twice daily for 30 days followed by CS treatment orally for another 14 days.

\section{Specimens collection and preparation}

Urine samples were accumulated during the experimental period from each group by metabolic cages then centrifuged for $10 \mathrm{~min}$ at $1500 \mathrm{rpm}$. At end of the experiment (after $24 \mathrm{~h}$ of the last injection), rats were fasted for 16-18 h then anesthetized through slight exposure to diethyl ether. Before sacrificing, blood samples were drawn from retro-orbital plexus and allowed for clotting at room temperature and then centrifuged at $3000 \mathrm{rpm}$ for $15 \mathrm{~min}$; the serum was separated and kept in clean stoppered vials at $20^{\circ} \mathrm{C}$ until the biochemical assay. After sacrificing the animals by cervical dislocation, the kidney tissues were dissected and washed in ice-cold saline. Portion of renal tissues was taken and immediately fixed in $10 \%$ formal saline for histopathological examination. Another portion was immediately fixed in glutaraldehyde for ultrastrcucture examination by electron microscope. $0.2 \mathrm{~g}$ of kidney tissue was homogenized in $3 \mathrm{~mL} \mathrm{pH} \mathrm{7.4} \mathrm{Tris-} \mathrm{HCl}$ buffers that contained 0.25 $\mathrm{M}$ sucrose by a motor-driven tissue homogenizer. The tissue homogenates were centrifuged at 2000 rpm for $10 \mathrm{~min}$ for settling down the cell debris and unbroken cells. The supernatants were pipetted into eppendorff tubes and stored at $-80^{\circ} \mathrm{C}$ till to be assayed.

\section{Biochemical analysis}

The Li levels were quantified in serum samples by inductively coupled plasma-optical emission spectrometry (Varian Co). Serum urea, uric acid, creatinine, total protein and blood urea nitrogen (BUN) were measured in all experimental animals by standard spectrophotometric methods using commercially available kits obtained from Spectrum Diagnostics Egyptian Company for Biotechnology (Cairo, Egypt).

The urinary NAG level was measured in the clear supernatants of urine samples spectrophotometrically at $580 \mathrm{~nm}$ as 3-cresol sulfonphthalein released from 3 -cresol sulfonphthaleinyl $\beta$-D-glucosaminide according to the method described by Yakata et al. (1983). Furthermore, creatinine was measured in urine using standard spectrophotometric methods and hence urinary NAG/creatinine ratio was calculated.

\section{Markers of the oxidative stress}

The lipid peroxidation product (LPO) was determined in the renal tissue homogenates spectrophotometrically at wavelength $535 \mathrm{~nm}$ using a UV-vis spectrophotometer (Shimadzu uv-2401 pc) according to method suggested by Ohkawa et al. (1979).

The total $(\mathrm{Cu}-\mathrm{Zn}$ and $\mathrm{Mn})$ superoxide dismutase (SOD) activity was assayed and expressed as units per gram protein $(\mathrm{U} / \mathrm{g})$ in renal tissue homogenates based on method suggested by Sun et al. (1988) and a slightly modified by Durak et al. (1993). Catalase (CAT) activity was measured spectrophotometrically in the presence of hydrogen peroxide $\left(\mathrm{H}_{2} \mathrm{O}_{2}\right)$ as substrate according to method Aebi (1984) who suggested that activities of the enzymes were expressed as $\mathrm{k}$ (rate constant) per gram $(\mathrm{k} / \mathrm{g})$ protein. The glutathione peroxidase (GPx) activity was measured based on the method described by Paglia and Valentine (1967). The enzymatic reaction was consisting of reduced nicotinamide adenine dinucleotide phosphate, reduced glutathione, sodium azide and glutathione reductase. It was initiated by addition of $\mathrm{H}_{2} \mathrm{O}_{2}$ as substrate and the change in absorbance was monitored spectrophotometerically at wavelength 340 $\mathrm{nm}$. The enzyme activity was given in units per gram protein $(\mathrm{U} / \mathrm{g})$. Furthermore, the reduced glutathione (GSH) content was assayed in tissue homogenates through the reaction with $5.5^{\prime}$-dithio-bis-2-nitrobenzoic acid (DTNB) to form product measured 
spectrophotometrically at $412 \mathrm{~nm}$. The result was expressed as $\mu \mathrm{mol}$ of GSH per mg of protein ( $\mu \mathrm{mol}$ $\mathrm{GSH} / \mathrm{mg}$ protein) (Ellman 1959).

\section{Histopathological examination}

The renal specimens were prepared according to method described by Banchroft et al. (1996). The specimens were washed in tap water then dehydrated in serial dilutions of alcohol solutions. Tissue fragments were cleared in xylene and embedded in paraffin. Paraffin bees wax tissue blocks were prepared for sectioning at $4 \mu \mathrm{m}$ thickness using sledge microtome. The tissue sections were collected on glass slides and stained by hematoxylin \& eosin (H\&E) then studied under the light electric microscope.

\section{Scanning microscopic examination}

The ultrastructural examination was carried out in specimens autopsied from renal tissues using scanning electron microscope (SEM). The tissues were preserved in gluteraldehyde for $24 \mathrm{~h}$ and processed according to method suggested by Tánaka (1989) and modified by Kiernan (2000) who reported that the specimen dehydrated through series of the alcoholic solutions. At end of the last dehydration step, the specimens were incubated at $37^{\circ} \mathrm{C}$ for $15 \mathrm{~min}$ and then coated with the golden atoms to be ready for the examination by electron microscope.

\section{Statistical analysis}

Data for all animal groups were represented by mean \pm standard error (SE) of eight individual values. Data of all groups were compared using one-way analysis of variance (ANOVA) followed by the Bonferroni multiple comparison tests. Pearson correlation between the study parameters was calculated. The probability of $p<0.05$ was considered significant.

\section{Results}

All the rats survived the experimental period until sacrifice. It was found that $\mathrm{Li}$ was completely absent in sera of control and CS-treated groups. The Li-treated and CS simultaneous and post-treated groups were noticed with high serum-Li concentrations $(0.42 \pm 0.01,0.40 \pm 0.02$, and $0.41 \pm 0.01 \mathrm{mmol} / \mathrm{l}$, respectively). It was noticed that $\mathrm{CS}$ reduced the $\mathrm{Li}$ concentration significantly $(P<0.05)$ in serum of the CS pre-treated group $(0.162 \pm 0.002 \mathrm{mmol} / \mathrm{l})$ when compared to other Li-treated groups.

Based on data depicted in Table 1, it was found that lithium caused significant $(P<0.05)$ elevation in serum urea, creatinin and BUN associated with significant $(P<0.05)$ decline in serum uric acid and T. protein. Moreover, it increased the urinary excretion of NAG significantly $(P<$ $0.05)$ as illustrated in Fig. 1. Administration of CS restored levels of these measurements to normalcy in CS pre-treated group through lowering urea, creatinin and BNU levels significantly $(P<0.05)$ with respect to Li-treated group. Although CS could not restore these measurements to normal values in CS simultaneous and post-treated groups, it decreased their levels significantly $(P<0.05)$ as compared to Li-treated group. Furthermore, CS increased levels of $\mathrm{T}$. protein and uric acid to be normal in CS pre-treated group. While in CS simultaneous and post-treated groups, CS could not restore these measurements to normal levels but it enhanced their levels significantly $(P<0.05)$ with respect to Li-treated group.

As illustrated in Fig. 2, it was found that the renal LPO level increased significantly $(P<0.05)$. As revealed in Table 2, levels of the antioxidant measurements (SOD, CAT, GPx, and GSH) decreased significantly $(P<0.05)$ in renal tissue of the Li-treated group in comparison with control group.

The treatment with CS reduced the renal LPO significantly $(P<0.05)$ associated with stimulating the antioxidant system by increasing levels of SOD, CAT, GPx, and GSH significantly $(P<0.05)$ in the renal tissue as compared to Li-treated group. It was emphasized that CS restored levels of the antioxidants in the pre-treated group to normal values. While in CS simultaneous and post-treated groups, CS could not restore their values to normalcy, but it exhibited improvement through enhancing their values (except LPO and GSH levels) with respect to Li-treated group.

Table 1 Prophylactic and therapeutic effect of chitosan on renal functions against $\mathrm{Li}_{2} \mathrm{CO}_{3}$ induced renal toxicity in rats

\begin{tabular}{lllllll}
\hline & $C$ & CS & Li & Pre-treated & Sim-treated & Post-treated \\
\hline Urea $(\mathrm{mg} / \mathrm{dl})$ & $26.96 \pm 0.30$ & $26.47 \pm 0.21$ & $49.10 \pm 0.16^{\mathrm{a}}$ & $27.22 \pm 0.41^{\mathrm{b}}$ & $38.48 \pm 0.25^{\mathrm{ab}}$ & $39.39 \pm 0.36^{\mathrm{b}}$ \\
Creatinin (mg/dl) & $0.73 \pm 0.01$ & $0.75 \pm 0.01$ & $2.22 \pm 0.02^{\mathrm{a}}$ & $0.78 \pm 0.01^{\mathrm{b}}$ & $1.71 \pm 0.02^{\mathrm{ab}}$ & $1.85 \pm 0.02^{\mathrm{ab}}$ \\
BUN (mg/dl) & $8.17 \pm 0.09$ & $8.02 \pm 0.06$ & $14.88 \pm 0.05^{\mathrm{a}}$ & $8.25 \pm 0.12^{\mathrm{b}}$ & $11.66 \pm 0.08^{\mathrm{ab}}$ & $11.94 \pm 0.11^{\mathrm{ab}}$ \\
T. protein (g/dl) & $8.19 \pm 0.03$ & $8.09 \pm 0.04$ & $4.01 \pm 0.08^{\mathrm{a}}$ & $7.89 \pm 0.10^{\mathrm{b}}$ & $5.28 \pm 0.02^{\mathrm{ab}}$ & $5.89 \pm 0.06^{\mathrm{ab}}$ \\
Uric acid (mg/dl) & $4.22 \pm 0.03$ & $4.29 \pm 0.06$ & $0.80 \pm 0.01^{\mathrm{a}}$ & $4.31 \pm 0.04^{\mathrm{b}}$ & $1.61 \pm 0.01^{\mathrm{ab}}$ & $1.48 \pm 0.01^{\mathrm{ab}}$ \\
\hline
\end{tabular}

Values are expressed as mean \pm SE for 8 rats per group

${ }^{a}$ Statistically difference in comparison with control group (significant at $P<0.05$ )

${ }^{b}$ Statistically difference in comparison with Li-treated group (significant at $P<0.05$ ) 


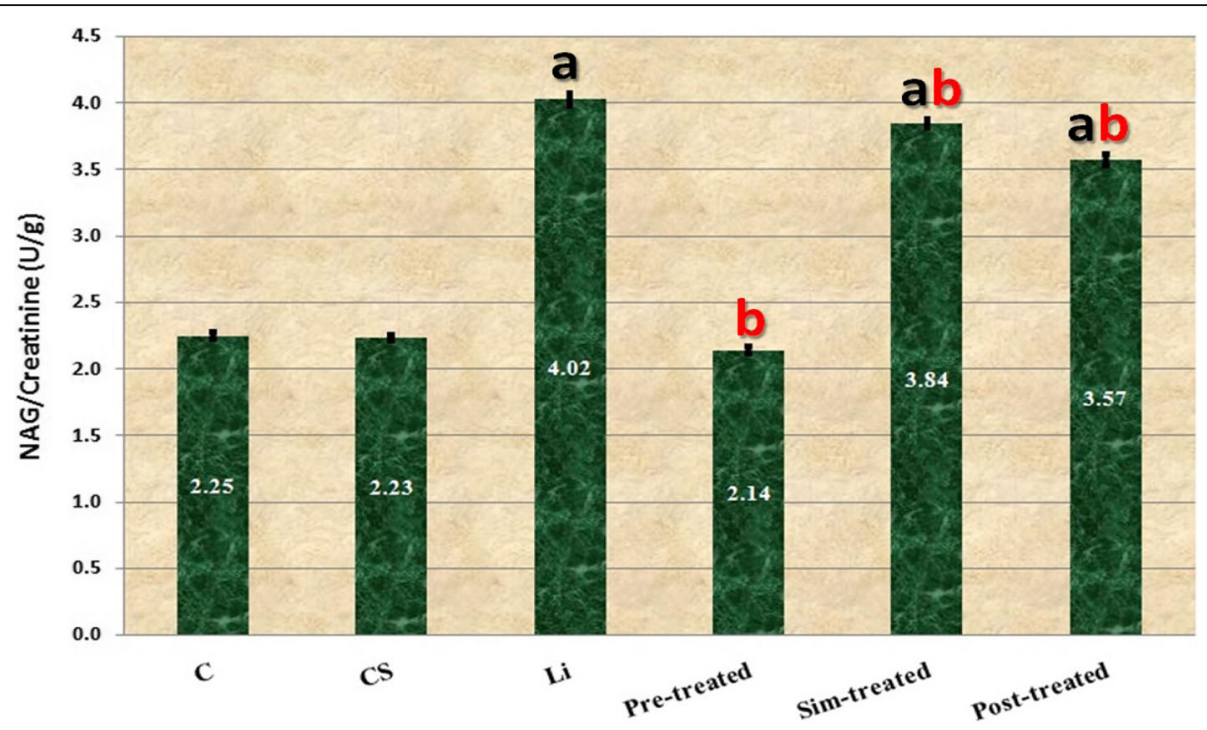

Fig. 1 Prophylactic and therapeutic effect of chitosan on urinary NAG/creatinine ( $\mathrm{N}$-acetyl- $\beta$-D-glucosaminidase/creatinine) ratio against $\mathrm{Li}_{2} \mathrm{CO}_{3}$-induced renal toxicity in rats. Bars represent the group means \pm SE. a Significant difference from control group at $P<0.05$. $\mathbf{b}$ Significant difference from Li-treated group at $P<0.05$

It was revealed that there were no histopathological alterations in kidney of control rats. As presented in Fig. 3a, the glomeruli and tubules were recorded at the cortex with normal histological structure. In CS-treated group, there was no histopathological alteration and no deviation from control group (Fig. 3b). While in Li-treated group, there was vacuolization in the endothelial cells lining tufts of the glomeruli with degeneration in the surrounding tubules (Fig. 3c). In contrast, in CS pre-treated group, there was no histological alteration of the glomeruli and tubules (Fig. 3d). In CS simultaneous-treated group, congestion was detected in the cortical blood vessels (Fig. 3e). Also, in CS post-treated group, there was congestion in the cortical blood vessels (Fig. 3f).

As presented in the electron micrograph (Fig. 4a), the renal ultrastructure of control and CS-treated groups showed normal architecture. Administration of CS alone

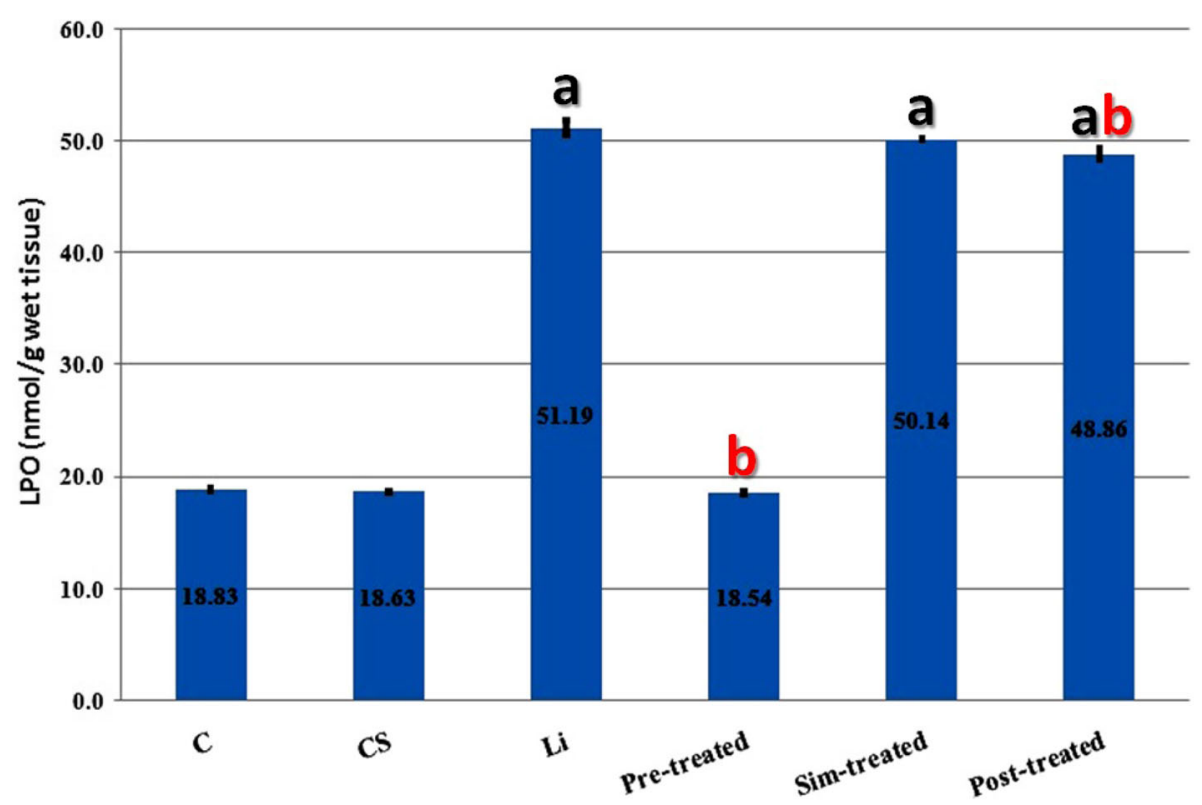

Fig. 2 Prophylactic and therapeutic effect of chitosan on renal $L P O$ (lipid peroxidation product) level against $\mathrm{Li}_{2} \mathrm{CO}_{3}$-induced renal toxicity in rats. Bars represent the group means \pm SE. a Significant difference from control group at $P<0.05$. b Significant difference from Li-treated group at $P<0.05$ 
Table 2 Prophylactic and therapeutic effect of chitosan on activities of the antioxidants against $\mathrm{Li}_{2} \mathrm{CO}_{3}$-induced renal toxicity in rats

\begin{tabular}{lllllll}
\hline & C & CS & Li & Pre-treated & Sim-treated & Post-treated \\
\hline SOD (U/g protein) & $0.86 \pm 0.01$ & $0.82 \pm 0.01$ & $0.48 \pm 0.01^{\mathrm{a}}$ & $0.80 \pm 0.01^{\mathrm{b}}$ & $4.20 \pm 0.02^{\mathrm{ab}}$ & $4.12 \pm 0.05^{\mathrm{ab}}$ \\
CAT (k/g protein) & $556.28 \pm 1.77$ & $551.03 \pm 1.41$ & $348.17 \pm 3.36^{\mathrm{a}}$ & $550.47 \pm 0.73^{\mathrm{b}}$ & $370.47 \pm 1.94^{\mathrm{ab}}$ & $379.82 \pm 2.83^{\mathrm{ab}}$ \\
Gpx (U/g protein) & $569.48 \pm 1.12$ & $572.33 \pm 0.96$ & $335.21 \pm 1.44^{\mathrm{a}}$ & $567.30 \pm 1.22^{\mathrm{b}}$ & $325.50 \pm 1.07^{\mathrm{ab}}$ & $329.89 \pm 1.04^{\mathrm{ab}}$ \\
GSH ( $\mu$ mol/mg protein) & $3.93 \pm 0.06$ & $3.83 \pm 0.03$ & $1.88 \pm 0.02^{\mathrm{a}}$ & $3.78 \pm 0.05^{\mathrm{b}}$ & $1.87 \pm 0.06^{\mathrm{a}}$ & $2.21 \pm 0.05^{\mathrm{ab}}$ \\
\hline
\end{tabular}

Values are expressed as mean \pm SE for 8 rats per group

${ }^{a}$ Statistically difference in comparison with control group (significant at $P<0.05$ )

${ }^{\mathrm{b}}$ Statistically difference in comparison with Li-treated group (significant at $P<0.05$ )

displayed no alterations in the tissue surface with respect to control (Fig. 4b). Obvious lesions were noticed in kidney of Li-treated group and represented by deep irregular cracking (red arrow) with cellular bridging (Fig. 4c).

In the CS pre-treated group, CS exhibited beneficial effect against the necrotic effect induced by $\mathrm{Li}$ and improved the kidney architecture where the renal tissue appeared unchanged and smooth in this group with some blood aggregates (yellow arrow) (Fig. 4d). In the CS simultaneous and post-treated groups (Fig. 4e, f), there were severe ultrastructural alterations represented by deep irregular cracking (red arrow) associated with cellular bridging (black arrow) and cellular lose.

\section{Discussion}

Lithium is considered as the first therapeutic line in patients with bipolar affective disorders (Boton et al.
1987). It is well known that nephrotoxicity that is represented by impairment of the concentrating ability and renal tubular damage can be categorized as the most common adverse Li effect (Markowitz et al. 2000; Prense et al. 2003).

In the present study, it was found that the Li concentration increased in sera of Li-treated rats. This was in accordance to Zhang et al. (2009) who reported that the Li doses resulted in serum levels of $<0.9 \mathrm{mmol} / \mathrm{L}$, which is the lower normal therapeutic serum level for bipolar disorder. CS showed an effective role in decreasing the $\mathrm{Li}$ concentration especially in sera of the CS pre-treated group. This was in agreement with Toz and Değer (2018) who showed that CS was able to in remove the bivalent metals from the circulatory system effectively and enforced the defense (antioxidant) system against free radicals attack. Furthermore, Wang et al. (2016) revealed that efficacy of

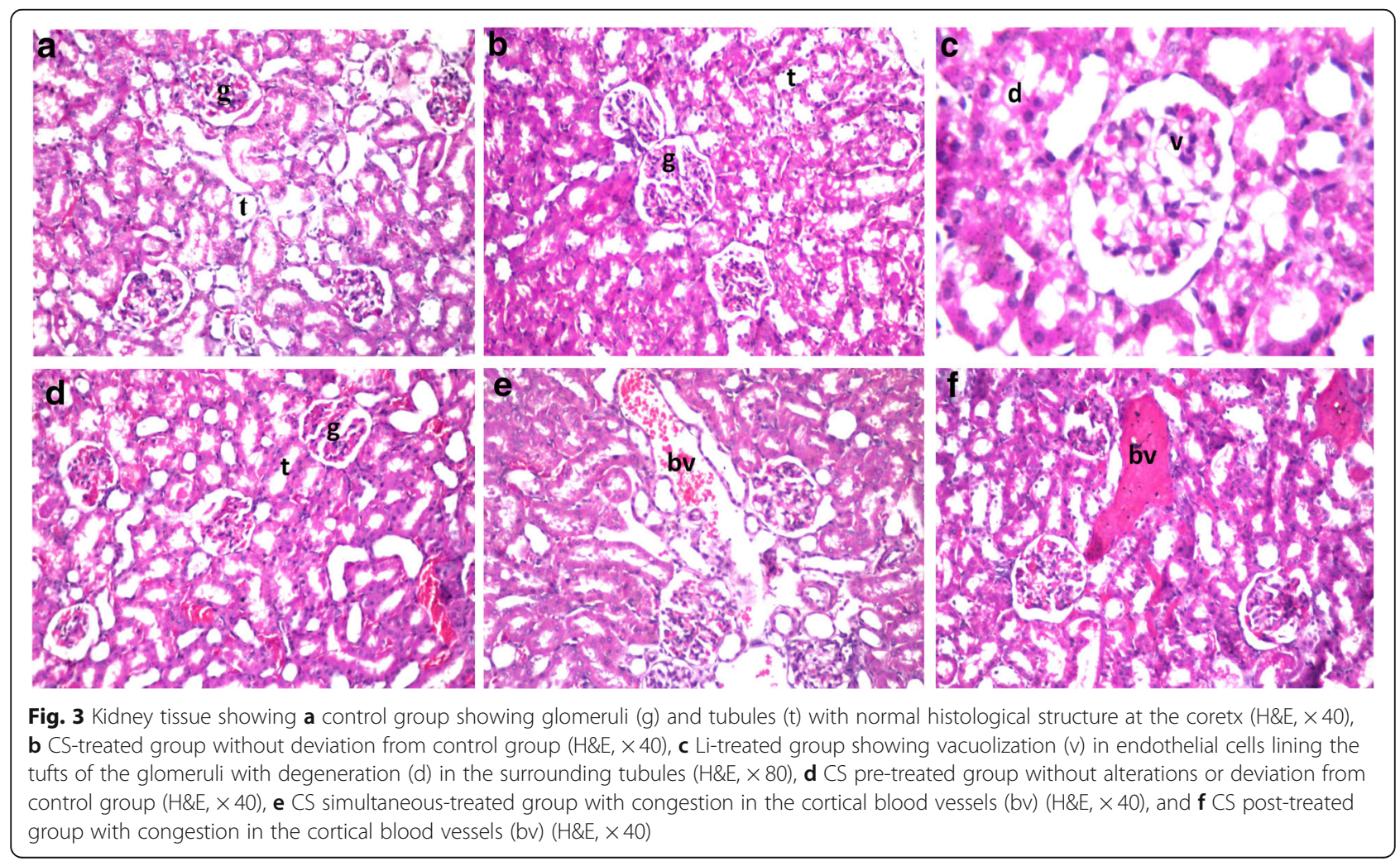



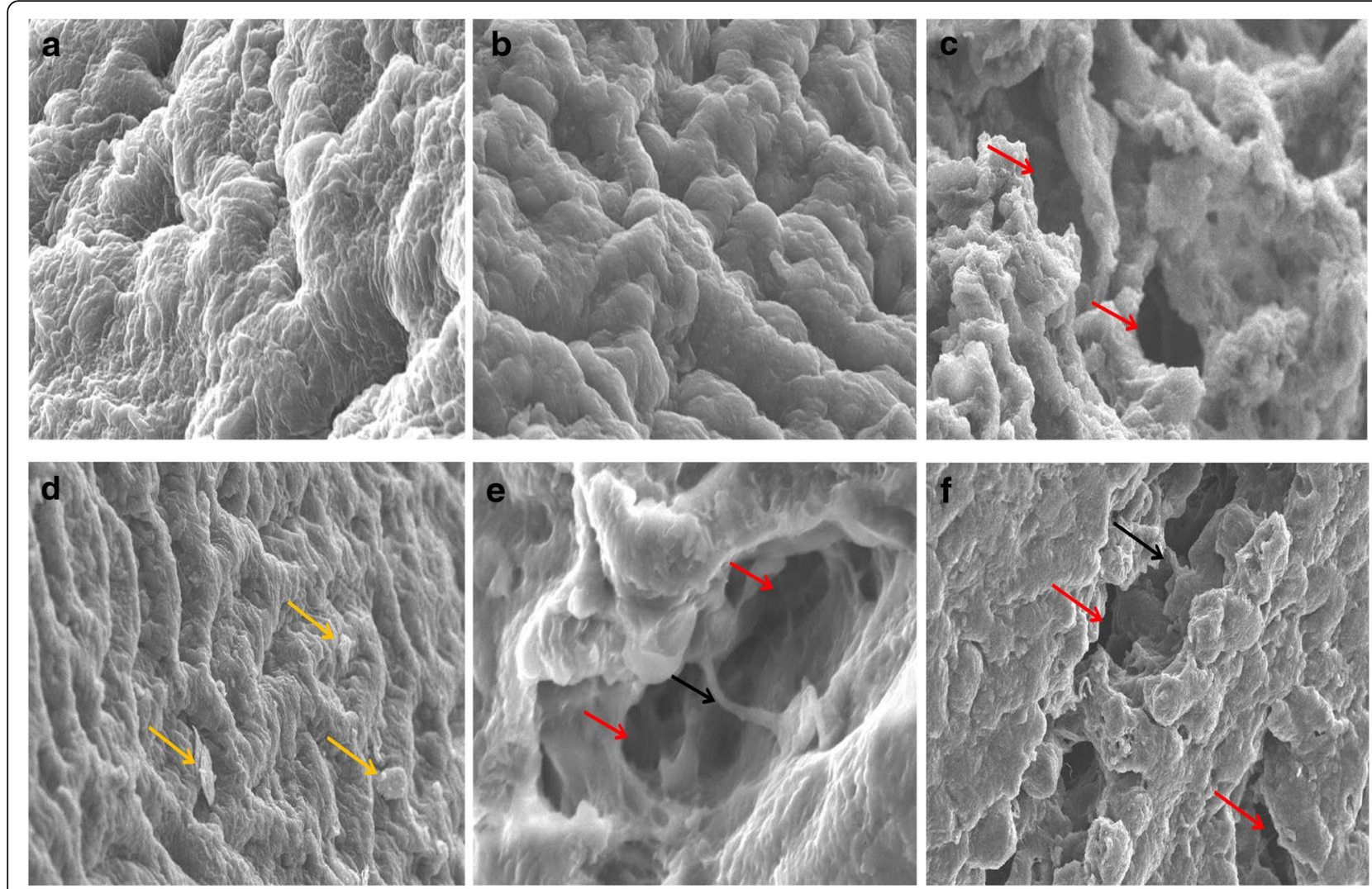

Fig. 4 Scanning electromicrograph in renal tissue showing a control group with normal ultrastructure $(\times 1500)$, b CS-treated group without deviation from control group ( $\times 1300)$, c Li-treated group with obvious lesions represented by deep irregular cracking with cellular bridging ( $\times 1300)$, d CS pre-treated group without alterations or deviation from control group $(\times 1000)$, e CS simultaneous-treated group with severe ultrastructural alterations represented by deep irregular cracking with cellular bridging $(\times 1700)$, and $\mathbf{f}$ CS post-treated group with ultrastructural variations represented by irregular cracking with cellular bridging in addition to cellular lose $(\times 1000)$

CS might be increased when taken in conjunction with a suitable chelator for eliminating metal from the circulation.

Lithium affects both kidneys at different levels and this effect is expressed by a series of physiologic changes (Mwaheb et al. 2016). It was found that presence of $\mathrm{Li}$ in the carbonate form increases the selective permeability of lithium and sodium. This might be attributable to the ability of carbonate to produce ion pairs with them (Ullah and Khan 2014). Polyuria is considered as the most adverse side effects of $\mathrm{Li}$. This might refer to ability of $\mathrm{Li}$ to replace sodium or potassium in the cell. Consequently, this leads to alteration in salt, water and electrolyte handling (Bedford et al. 2008; Mwaheb et al. 2016).

It was found that $\mathrm{Li}$ caused significant increase in measurements of the renal functions (urea, creatinine and BUN). This was in accordance with Ahmed et al. (2011) and supported recently by Mwaheb et al. (2016) who notify that $\mathrm{Li}$ is able to stimulate the toxicity at physiological and histopathological grades in renal tissues of rats. Moreover, the severe elevation in renal functions related to renal tissues lesions (Cherpakov et al. 2015). The CS administration resulted in a significant decrease in levels of these measurements as compared with Li-treated group. This was in accordance with the study carried out by Anraku et al. (2012) who postulated that CS resulted in a significant reduction in levels of the pro-oxidants thereby inhibiting the subsequent development of oxidative stress.

As suggested by Toplan et al. (2013) and supported by Weiner et al. (2014), it was emphasized that the proximal tubule represents the primary site through which $\mathrm{Li}$ is reabsorbed and accumulates in the distal parts of the nephron through the epithelial sodium channel. Therefore, it is considered as one of the reasons which lead to reducing levels of serum uric acid and $\mathrm{T}$. protein associated with elevation of urinary excretion of NAG and renal LPO level. Moreover, these biochemical abnormalities in renal tissues may occur as a result of effect of the oxidative stress which represents one of the important deleterious mechanisms of Li. Consequently, this leads to generation of the reactive oxygen species (ROS) and hence induces renal impairment (Oliveira et al. 2010). In 
addition, the urinary excretion of NAG might be elevated as a result of the deleterious effect of $\mathrm{Li}$ at early stage in the renal tubuli (Jeon et al. 2003; Bosomworth et al. 1999). CS showed effective role in lowering the urinary excretion of NAG and the renal LPO. This might refer to the effective role of CS against attack of hydroxyl radicals and hence inhibiting peroxidation of phosphatidylcholine and linoleate liposomes (Jeon et al. 2003; Ozcelik et al. 2014).

In the renal tissues, there were various antioxidants to prevent the lesions occurred as a result of attack the excessive oxygen metabolites. They act either by decomposing peroxide or trapping the free radicals. Both CAT and GPx together play the same action through stimulating $\mathrm{H}_{2} \mathrm{O}_{2}$ to water. SOD is a specific antioxidant enzyme that dismutates $\mathrm{O}^{-2}$, forming $\mathrm{H}_{2} \mathrm{O}_{2}$, which is scavenged by peroxisomal CAT or GPx. In addition, it protects the cell against the deleterious effect of superoxide radicals. The extracellular SOD distributes in vessel walls of the renal tissue to detoxify the superoxide anions produced in sera of oxidative stress-exposed rats (Fadillioglu et al. 2003; Yilmaz et al. 2004).

GPx plays a vital role in removing $\mathrm{H}_{2} \mathrm{O}_{2}$ and lipid hydroperoxides through using reduced glutathione (GSH) as a hydrogen donor. During this reaction, GPx converts glutathione from the reduced (GSH) to its oxidized form (GSSG). In return, the cells utilize glutathione reductase to stimulate recycling GSSG to GSH (Zasadowski et al. 2004; Ilhan et al. 2004). As a result of lowering GPx activity, the $\mathrm{H}_{2} \mathrm{O}_{2}$ increased and subsequently leads to elevation of LPO and hence increasing the urinary NAG excretion.

As revealed during the present study, Li caused significant alterations in the antioxidant system in the renal tissue by lowering levels of enzymatic and non-enzymatic antioxidants. These results coincide with other study carried out by Oktem et al. (2005) who reported that these alterations might be attributed to the increased oxidative stress that leads to an over consumption of these antioxidants. Therefore, lowering the renal antioxidants indicates a high degree of oxidative stress leading to enhancement of the endogenous $\mathrm{H}_{2} \mathrm{O}_{2}$. As illustrated in results of the current study and supported by Mueller et al. (1997), the reduced LPO is accompanied by increased activities of CAT and GPx that are responsible for $\mathrm{H}_{2} \mathrm{O}_{2}$ elimination through its conversion into water and alcohol. Moreover, stimulation of the oxidative stress might refer to adverse effect of $\mathrm{Li}$ on the mitochondrial membranes which represent the major site for the mitochondrial respiratory chain and production of superoxide radicals $\left(\mathrm{O}^{-2}\right)$ (Nicholls and Budd 2000). This leads to generation of excess amounts of oxygen radicals and subsequently causes extreme use of SOD in rat kidneys (Toplan et al. 2016). The treatment with CS significantly increased SOD, CAT and GSH in the renal tissues as compared with Li-treated group. This was in accordance with Wang et al. (2016) who reported that CS exhibited efficacy against oxidative stress through reducing the LPO levels associated with elevation in activities of the antioxidant enzymes. Moreover, it elevated the GSH level although it does not have a known stimulating effect on GSH biosynthesis. CS exhibits beneficial effect on the antioxidant system by same mechanism of taurine through inhibiting the peroxidation reactions, thereby mitigating the GSH consumption and hence activating the antioxidant enzymes (Toz and Değer 2018).

Based on the histopathological investigation carried out at end of the experiment, it was noticed that $\mathrm{Li}$ caused various deformative alterations represented by damage of the epithelium lining of the glomeruli in renal tissue without signs of cellular proliferation as illustrated in the histopathological picture of the renal tissues. This was in accordance with Sharma and Iqbal (2005) and supported recently by Mwaheb et al. (2016) who suggested that lesions of the renal tissue might refer to the central role of oxidative stress in the pathogenesis process induced by ROS attack.

The SEM has become a powerful and suitable tool to study the morphological and ultrastructural alterations in the kidney tissue (Vodenicharov 2007). The renal ultrastructure examined by SEM has demonstrated severe lesions represented by deep irregular cracking with cellular bridging in surfaces of the renal tissues, implicating nephrotoxicity as one of the most important deleterious mechanisms of Li. Furthermore, in case of discontinuation of $\mathrm{Li}$ therapy, the renal deteriorate may continue as insidious and progressive (Markowitz et al. 2000). This might be due to effect of nitric oxide (NO) generated as a result of inducible nitric oxide synthase and responsible for the tissue damage. Consequently, peroxynitrite anions generated in the tubular epithelium as a result of the interaction of $\mathrm{NO}$ with superoxide anions $\left(\mathrm{O}_{2}\right)$ has the potential to alter the adhesion properties of tubular cells (Hierholzer et al. 1998; EMcKim et al. 2003). It was noticed that CS exhibited a renoprotective effects against renal lesions through reducing the free radicals in addition to its role in reducing deleterious effect of carbonyl groups. Moreover, Chou et al. (2015) postulated that CS showed a positive antagonistic effect by mechanism similar to that of metformin (standard drug) and may thus be a promising new treatment to protect against gentamicin-induced nephrotoxicity. 


\section{Conclusions}

The current study provides a clear experimental evidence for promising role of CS in the protection against the oxidative stress and renal toxicity induced by $\mathrm{Li}$. This is attributed to presence of polymeric biologically active compounds derived from chitin and exhibit antioxidant activities. Thus, CS was able to show its efficiency to improve renal toxicity when it can be used alone as a preventive agent without conjunction with chelating agents.

\section{Abbreviations \\ ANOVA: One-way analysis of variance; BUN: Blood urea nitrogen; CAT: Catalase; CS: Chitosan; DTNB: 5.5'-dithio-bis-2-nitrobenzoic acid; GPx: Glutathione peroxidase; GSH: Reduced glutathione; H\&E: Hematoxylin and eosin; $\mathrm{H}_{2} \mathrm{O}_{2}$ : Hydrogen peroxide; Li: Lithium; $\mathrm{Li}_{2} \mathrm{CO}_{3}$ : Lithium carbonate; LPO: Lipid peroxidation product; NAG: N-acetyl- $\beta$-D-glucosaminidase; NO: Nitric oxide; ROS: Reactive oxygen species; SE: Standard error; SEM: Scanning microscopic examination; SOD: Superoxide dismutase}

\section{Acknowledgements}

The authors are deeply grateful to Prof. Dr. Adel M.B. Kholoussy, Pathology Department, Faculty of Veterinary Medicine, Cairo University, Egypt for his effective role in carrying out the histopathological examination.

\section{Funding}

There was no fund or financial support provided to this work. The authors were responsible for cost of the animals and materials consumed during the experiments.

\section{Availability of data and materials}

The authors have ready to send data and the detailed scientific materials if it is useful for readings.

\section{Authors' contributions}

Both authors carried out literature review and draft the manuscript. Wael $M$ Aboulthana carried out the experimental work. Noha E. Ibrahim participated in the collection of data and arranged in tabular form. Both authors read and approved the final manuscript.

\section{Ethics approval and consent to participate}

The study was carried out on the experimental animals. They were handled according to the experimental protocol which was approved by Institutional Animal Ethics Committee of National Research Centre, Dokki, Giza, Egypt and were conducted in accordance with guidelines as per "Guide for the care and use of laboratory animal" and with permission from Committee for the Purpose of Control and Supervision of Experiments on Animals.

\section{Consent for publication}

Not applicable

\section{Competing interests}

The present study aimed to optimize CS as a promising protector against oxidative stress and renal toxicity induced by Li in the hope that this compound may be further explored as novel antioxidative protector. The authors declare that they have no competing interests.

\section{Publisher's Note}

Springer Nature remains neutral with regard to jurisdictional claims in published maps and institutional affiliations.

\section{Author details}

${ }^{1}$ Biochemistry Department, Genetic Engineering and Biotechnology Division, National Research Centre (Affiliation ID: 60014618), P.O. 12622, Dokki, Giza, Egypt. ${ }^{2}$ Microbial Biotechnology Department, Genetic Engineering and Biotechnology Division, National Research Centre (Affiliation ID: 60014618), P.O. 12622, Dokki, Giza, Egypt.
Received: 12 July 2018 Accepted: 11 November 2018

Published online: 20 December 2018

\section{References}

Adityanjee KR, Munshi A (2005) Thampy, the syndrome of irreversible lithium-effectuated neurotoxicity. Clin Neuropharmacol 28:38-49

Aebi $Y$ (1984) Catalase in vitro. Methods Enzymol 105:121-126

Ahmed M, EL Nakdy Y, Farooq M, Wadaan M (2011) Lithium induced toxicity in rats: blood serum chemistry, antioxidative enzymes in red blood cells and histopathological studies. Biol Pharm Bull 34:272-277

Albert U, DeCori D, Blengino G, Bogetto F, Maina G (2014) Lithium treatment and potential long-termside effects: asystematic review of the literature. Riv Psichiatr 49:12-21

Anraku M, Tomida H, Michihara A, Tsuchiya D, lohara D, Maezaki Y et al (2012) Antioxidant and renoprotective activity of chitosan in nephrectomized rats. Carbohydr Polym 89(1):302-304

Banchroft JD, Stevens A, Turner DR. Theory and Practice of Histological Techniques. 4th. Churchil Livingstone, New York, London, San Francisco, Tokyo; 1996

Bedford JJ, Weggery S, Ellis G, McDonald FJ, Joyce PR, Leader JP et al (2008) Lithium-induced nephrogenic diabetes insipidus: renal effects of amiloride. Clin J Am Soc Nephrol 3(5):1324-1331

Bocchetta A, Ardau R, Fanni T, Sardu C, Piras D, Pani A et al (2015) Renal function during long-term lithium treatment: a cross-sectional and longitudinal study. BMC Med 13:12

Bosomworth MP, Aparicio SR, Hay AWM (1999) Urine N-acetyl-beta-Dglucosaminidasea marker of tubular damage? Nephrol Dial Transplant 14:620-626

Boton R, Gaviria M, Batlle DC (1987) Prevalence, pathogenesis, and treatment of renal dysfunction associated with chronic lithium therapy. Am J Kidney Dis 5:329-345

Bravo-Osuna I, Millotti G, Vauthier C, Ponchel G (2007) In vitro evaluation of calcium binding capacity of chitosan and thiolated chitosan poly(isobutyl cyanoacrylate) core-shell nanoparticles. Int J Pharm 338:284-290

Calkin C, Alda M (2012) Beyond the guidelines for bipolar disorder: practical issues inlong-term treatment with lithium. Can J Psychiatr 57:437-445

Cherpakov RA, Grebenchikov OA, Plotnikov EJ, Likhvantsev W (2015) Dalargin and lithium ions in the model of gentamycin-induced acute renal failure. Anesteziol Reanimatol ARJ 60:58-63

Chmielnicka J, Nasiadek M (2003) The trace elements in response to lithium intoxication in renal failure. Ecotoxicol Environ Saf 55(2):178-183

Chou C, Li Y, Chen S, Shih Y, Lee J (2015) Chitosan Prevents Gentamicin-Induced Nephrotoxicity via a Carbonyl Stress-Dependent Pathway. BioMed Research International. Volume 2015, Article ID 675714, 8 pages

Cleare A, Pariante CM, Young AH, Anderson IM, Christmas D, Cowen PJ et al (2015) Evidence-based guidelines for treating depressive disorders with antidepressants: a revision of the 2008 British Association for Psychopharmacology guidelines. J Psychopharmacol 29(5):459-525

Clos S, Rauchhaus P, Severn A, Cochrane L, Donnan PT (2015) Long-term effect of lithium maintenance therapy on estimated glomerular filtration rate in patients with affective disorders: a population-based cohort study. Lancet Psychiatry 2(12):1075-1083

Close H, Reilly J, Mason JM, Kripalani M, Wilson D, Main J et al (2014) Renal failure in lithium-treated bipolar disorder: a retrospective cohort study. PLoS One 9(3):e90169

Crini G, Badot PM (2008) Application of chitosan, a natural aminopolysaccharide, for dye removal from aqueous solutions by adsorption processes using batch studies: a review of recent literature. Prog Polym Sci 33:399-447

Curran G, Ravindran A (2014) Lithium for bipolar disorder: a review of the recent literature. Expert Rev Neurother 14:1079-1098

Dong W, Han B, Feng Y, Song F, Chang J, Jiang H et al (2010) Pharmacokinetics and biodegradation mechanisms of a versatile carboxymethyl derivative of chitosan in rats: in vivo and in vitro evaluation. Biomacromolecules 11(6): $1527-1533$

Draper HH, Hadley M (1990) Malondialdehyde determination as index of lipid peroxidation. Methods Enzymol 186:421-431

Durak I, Yurtarslani Z, Canbolat O, Akyol O (1993) A methodological approach to superoxide dismutase (SOD) activity assay based on inhibition of nitroblue tetrazolium (NBT) reduction. Clin Chim Acta 214:103-104

Edwards SJ, Hamilton V, Nherera L, Trevor N (2013) Lithium or an atypical antipsychotic drug in the management of treatment-resistant depression: a systematic review and economic evaluation. Health Technol Assess 17(54):1-190 
Efrati S, Averbukh M, Berman S, Feldman L, Dishy V, Kachko L et al (2004) Nacetylcysteine ameliorates lithium induced renal failure in rats. Nephrol Dial Transplant 20:65-70

EIFar MMM, Taie HAA (2009) Antioxidant activities, total anthrocynins, phenolics and flavonoids contents of some sweet potato genotypes under stress of different concentrations of sucrose and sorbitol. Australian J Basic Applied Sc 3:3609-3616

Ellman GL (1959) Tissue sulfhydryls groups. Arch Biochem Biophys 82:70-77

EMcKim S, Gäbele E, Isayama F, Lambert JC, Tucker LM, Wheeler MD et al (2003) Inducible nitric oxide synthase is required in alcohol-induced liver injury: studies with knockout mice. Gastroenterology 125(6):1834-1844

Erdemoglu N, Turan NN, Cahoco I, Senor B, Aydon A (2006) Antioxidant activities of some Lamiaceae plant extracts. Phytother Res 20:9-13

Erden A, Karagoz H, Başak M, Karahan S, Cetinkaya A, Avci D et al (2013) Lithium intoxication and nephrogenic diabetes insipidus: a case report and review of literature. Int J Gen Med 6:535-539

Fadillioglu E, Erdogan H, Sogut S, Kuku I (2003) Protective effects of erdosteine against doxorubicin-induced cardiomyopathy in rats. J Appl Toxicol 23:71-74

Forlenza OV, Diniz BS, Radanovic M, Santos FS, Talib LL, Gattaz WF (2011) Disease-modifying properties of long-term lithium treatment for amnestic mild cognitive impairment: randomised controlled trial. Br J Psychiatry 198: 351-356

Gamage A, Shahidi F (2007) Use of chitosan for the removal of metal ion contaminants and proteins from water. Food Chem 104:989-996

Grunze H, Vieta E, Goodwin GM, Bowden C, Licht RW, Moller HJ et al (2010) The World Federation of Societies of Biological Psychiatry (WFSBP) guidelines for the biological treatment of bipolar disorders: update 2010 on the treatment of acute bipolar depression. World J Biol Psychiatry 11:81-109

Harish Prashanth KV, Tharanathan RN (2007) Chitin/chitosan: modifications and their unlimited application potential--an overview. Trends Food Sci Technol 18:117-131

Hierholzer C, Harbrecht B, Menezes JM, Kane J, MacMicking J, Nathan CF et al (1998) Essential role of induced nitric oxide in the initiation of the inflammatory response after hemorrhagic shock. J Exp Med 187:917-928

Ida S, Yokota M, Ueoka M, Kiyoi K, Takiguchi Y (2001) Mild to severe lithium-induced nephropathy models and urine $\mathrm{N}$-acetyl-beta-D-glucosaminidase in rats. Methods Find Exp Clin Pharmacol 23(8):445-448

Ilhan A, Gurel A, Armutcu F, Kamisli S, Iraz M, Akyol O et al (2004) Ginkgo biloba prevents mobile phone-induced oxidative stress in rat brain. Clin Chim Acta 340:153-162

Jeon TI, Hwang SG, Park NG, Jung YR, Shin SI, Choi SD, Park DK (2003) Antioxidative effect of chitosan on chronic carbon tetrachloride-induced hepatic injury in rats. Toxicology 187(1):67-73

Kalantari H, Salimi A, Rezaie A, Jazayeri Shushtari F, Goudarzi M (2015) Evaluation of sub-acute oral toxicity of lithium carbonate microemulsion (nano size) on liver and kidney of mice. Jundishapur Journal of Natural Pharmaceutical Products 10(1):e22312

Kiernan JA (2000) Formaldehyde, formalin, paraformaldehyde and glutaraldehyde: what they are and what they do. Microscopy Today 1:8-12

Leschiner S, Weizman R, Shoukrun R, Veenman L, Gavish M (2000) Tissue-specific regulation of the peripheral benzodiazepine receptor by antidepressants and lithium. Neuropsychobiology 42:127-134

Markowitz GS, Radhakrishnan J, Kambham N, Valeri AM, Hines WH, D'Agati VD (2000) Lithium nephrotoxicity: a progressive combined glomerular and tubulointerstitial nephropathy. J Am Soc Nephrol 11(8):1439-1448

McCartney Y, Browne C, Little DM, Gulmann C (2014) Lithium induced nephrotoxicity: a case report of renal cystic disease presenting as a mass lesion. Urol Case Rep 2:186-188

Mueller S, Riedel HD, Stremmel W (1997) Direct evidence for catalase as the predominant $\mathrm{H}_{2} \mathrm{O}_{2}$-removing enzyme in human erythrocytes. Blood 90: 4973-4978

Mwaheb MA, Sayed ON, Mohamed SH (2016) Protective effect of rosemary (Rosmarinus officinalis) extract on Lithium induced renal and testis toxicity in albino rats. J Drug Metab Toxicol 7:4

Neimert-Andersson T, Hällgren AC, Andersson M, Langebäck J, Zettergren L, Nilsen-Nygaard J et al (2011) Improved immune responses in mice using the novel chitosan adjuvant ViscoGel, with a Haemophilus influenzae type b glycoconjugate vaccine. Vaccine 29(48):8965-8973

Nicholls DG, Budd SL (2000) Mitochondria and neuronal survival. Physiol Rev $80: 315-360$
No HK, Park NY, Lee SH, Meyers SP (2002) Antibacterial activity of chitosans and chitosan oligomers with different molecular weights. Int J Food Microbiol 74(1-2):65-72

Ohkawa H, Ohishi N, Nagi K (1979) Assay of lipid peroxides in animal tissue by thiobarbituric acid reaction. Anal Biochem 95(2):351-358

Oktem F, Ozguner F, Sulak O, Olgar S, Akturk O, Yilmaz HR et al (2005) Lithium-induced renal toxicity in rats: protection by a novel antioxidant caffeic acid phenethyl ester. Mol Cell Biochem 277:109-115

Oliveira $J$, Silva Júnior GB, Abreu KL, Rocha Nde A, Franco LF, Araújo SM et al (2010) Lithium nephrotoxicity. Rev Assoc Med Bras 56:600-606

Oruch R, Elderbi MA, Khattab HA, Pryme IF, Lund A (2014) Lithium: a review of pharmacology, clinical uses, and toxicity. Eur J Pharmacol 740:464-473

Ozcelik E, Uslu S, Erkasap N, Karimi H (2014) Protective effect of chitosan treatment against acetaminophen-induced hepatotoxicity. Kaohsiung J Med Sci 30:286-290

Paglia DE, Valentine WN (1967) Studies on the quantitative and qualitative characterization of erythrocyte glutathione peroxidase. J Lab Clin Med 70:158-169

Park JH, Cho YW, Chung H, Kwon IC, Jeong SY (2003) Synthesis and characterization of sugar-bearing chitosan derivatives: aqueous solubility and biodegradability. Biomacromolecules 4(4):1087-1091

Prense C, Fakhouri F, Noël LH, Stengel B, Even C, Kreis H et al (2003) Lithiuminduced nephropathy: rate of progression and prognostic factors. Kidney Int 64:585-592

Qi L, Xu Z (2006) In vivo antitumor activity of chitosan nanoparticles. Bioorg Med Chem Lett 16:4243e5

Rajkapoor B, Venigopal Y, Anbu J, Harikrishnan N, Gobinath M, Ravichandran V (2008) Protective effect of Phyllanthus polyphyllus on acetaminophen-induced hepatotoxicity in rats. Pak J Pharm Sci 21:57e62

Renault F, Sancey B, Badot PM, Crini G (2009) Chitosan for coagulation/ flocculation processes-an eco-friendly approach. Eur Polym J 45:1337-1348

Rinaudo M (2006) Chitin and chitosan: properties and applications. Prog Polym Sci 31(7):603-632

Samarasinghe RM, Kanwar RK, Kanwar JR (2014) The effect of oral administration of iron saturated-bovine lactoferrin encapsulated chitosan-nanocarriers on osteoarthritis. Biomaterials 35:7522-7534

Sawas AH, Gilbert JC, Watson ME (1986) Effects of lithium salts on lipid peroxidation activity of synaptosomes and kidney homogenates. Arch Int Pharmacodyn Ther 281(2):192-197

Sharma SD, lqbal M (2005) Lithium induced toxicity in rats: a hematological, biochemical and histopathological study. Biol Pharm Bull 28(5):834-837

Shen KT, Chen MH, Chan HY, Jeng JH, Wang YJ (2009) Inhibitory effects of chitooligosaccharides on tumor growth and metastasis. Food Chem Toxicol 47:1864-1871

Sun Y, Oberley LW (1988) Li Y. a simple method for clinical assay of superoxide dismutase. Clin Chem 34:497-500

Tánaka K (1989) High resolution scanning electron microscopy of the cell. Biol Cell 65:89-98

Toplan S, Dariyerli N, Ozdemir S, Ozcelik D, Zengin EU, Akyolcu MC (2013) Lithium-induced hypothyroidism: oxidative stress and osmotic fragility status in rats. Biol Trace Elem Res 152(3):373-378

Toplan S, Ozdemir S, Tanriverdi G, Akyolcu MC, Ozcelik D, Darıyerli N (2016) The effects of Lithium administration on oxidant/antioxidant status in rats: biochemical and Histomorphological evaluations. Biol Trace Elem Res 169(2):279-284

Toz H, Değer Y (2018) The effect of chitosan on the erythrocyte antioxidant potential of Lead toxicity-induced rats. Biol Trace Elem Res 184(1):114-118

Ullah H, Khan MF (2014) Mood stabilizing agent lithium carbonate depletes reduced glutathione in human erythrocytes during lithium toxicity. Gomal J Med Sci 12:237-240

Vieta E, Valenti M (2013) Pharmacological management of bipolar depression: acute treatment, maintenance, and prophylaxis. CNS Drugs 27:515-529

Vodenicharov A (2007) Scanning electron microscopic study on renal glomerular arterioles in pigs. Bulgarian Journal of Veterinary Medicine 10(3):147-154

Wang Z, Yan Y, Yu X, Li W, Li B, Qin C (2016) Protective effects of chitosan and its water-soluble derivatives against lead-induced oxidative stress in mice. Int J Biol Macromol 83:442-449

Weiner ID, Leader JP, Bedford JJ, Verlander JW, Ellis G, Kalita P et al (2014) Effects of chronic lithium administration on renal acid excretion in humans and rats. Physiol Rep 2(12):e12242

Xia W, Liu P, Zhang J, Chen J (2011) Biological activities of chitosan and chitooligosaccharides. Food Hydrocoll 25(2):170-179 
Yakata M, Sugita O, Sakai T, Uchiyama K, Wada K (1983) Urinary enzyme determination and its clinical significance. C. enzyme derived from the kidney tubular epithelium--N-acetyl-beta-D-glucosaminidase. 4. Preclinical evaluation of the urinary NAG activity and changes in renal diseases. Rinsho Byori 56:90-101

Yilmaz HR, Uz E, Yucel N, Altuntas I, Ozcelik N (2004) Protective effect of Caffeic Acid Phenethyl Ester (CAPE) on lipid peroxidation and antioxidant enzymes in diabetic rat liver. J Biochem Mol Toxicol 18:234-238

Zasadowski A, Wysocki A, Barski D, Spodniewska A (2004) Some aspects of reactive oxygen species (ROS) and antioxidative system agent's action. Short review. Acta Toxic 12:5-21

Zhang X, Aggarwal P, Li X, Oakman C, Wang Z, Rodriguez R (2009) The role of lithium carbonate and lithium citrate in regulating urinary citrate level and preventing nephrolithiasis. Int J Biomed Sci 5(3):215-222

\section{Submit your manuscript to a SpringerOpen ${ }^{\circ}$ journal and benefit from:}

- Convenient online submission

- Rigorous peer review

- Open access: articles freely available online

- High visibility within the field

- Retaining the copyright to your article

Submit your next manuscript at $\boldsymbol{\nabla}$ springeropen.com 